\title{
Inovasi Alternatif Perancangan Tampilan Website Berdasarkan Analisis Faktor Multivariat sebagai Bagian dari Implementasi Kansei Engineering
}

\author{
Arief Ginanjar \\ Program Studi Informatika \\ Universitas Langlangbuana \\ agienthea@gmail.com
}

\author{
Wahyu Purnama Sari \\ Program Studi Informatika \\ Universitas Langlangbuana \\ wahyu.purnama@unla.ac.id
}

\author{
Herlina \\ Program Studi Informatika \\ STT Mandala \\ lina.herlina55@gmail.com
}

\begin{abstract}
Multivariate Factor Analysis is one of the statistical calculation techniques to find the main determinants that most influence on a statistical data set. In the development of website appearance based on function and usability as well as involving the affection side of the user it will be in touch with Kansei Engineering. By using Kansei Engineering Type I researchers try to detect the side of users' affection towards commonly used website components. Based on the specimen data that has been used in previous studies, researchers tried to develop a discussion that previously focused more on Kansei Engineering into an alternative innovation using multivariate factor analysis. Data from surveys are processed using multivariate statistical approach which is Cronbach's Alpha, Coefficient Correlation Analysis, Principal Component Analysis, Factor Analysis and Partial Least Square that have been done in previous studies, researchers try to assimilate the component values from the two highest Factor Analysis results into new recommendation data. That has been combined completely with a new website component recommendation value compared with previous results at the most unit analysis factor.
\end{abstract}

Keywords: Multivariate Factor Analysis, Kansei Engineering, Factor Analysis, Website, Kansei Words

\begin{abstract}
Abstrak
Analisis Faktor Multivariat merupakan salah satu teknik perhitungan statistik untuk mencari faktor penentu utama yang paling berpengaruh terhadap sebuah kumpulan data statistik. Dalam pengembangan tampilan website berdasarkan fungsi dan kegunaan serta melibatkan sisi perasaan pengguna maka akan bersinggungan dengan Kansei Engineering. Dengan menggunakan Kansei Engineering Type I peneliti mencoba untuk mendeteksi sisi perasaan pengguna terhadap komponen website yang umum digunakan. Dengan berdasarkan data spesimen yang telah digunakan pada penelitian sebelumnya maka peneliti mencoba untuk mengembangkan bahasan yang sebelumnya lebih fokus kepada Kansei Engineering menjadi inovasi alternatif menggunakan analisis faktor multivariat. Data hasil survey terhadap pengguna diolah menggunakan pendekatan statistik multivariat Cronbach's Alpha, Coefficient Correlation Analysis, Principal Component Analysis, Factor Analysis serta Partial Least Square yang telah dilakukan dipenelitian terdahulu, kemudian peneliti mencoba mengasimilasikan komponen nilai dari dua hasil faktor analisis tertinggi menjadi data rekomendasi baru yang telah digabungkan dengan nilai rekomendasi komponen website yang sama sekali baru dibandingkan dengan hasil faktor analisis satuan sebelumnya.
\end{abstract}

Kata kunci: Analisis Faktor Multivariat, Kansei Engineering, Faktor Analisis, Website, Kansei Words

\section{Pendahuluan}

\subsection{Latar Belakang}

Pengembangan website dengan fokus perhatian terhadap bagaimana perasaan pengguna terhadap komponen-komponen website, maka Kansei Engineering merupakan salah satu acuan yang tepat untuk mendalami proses perancangan tersebut. Proses analisis yang terjadi terhadap elemen perasaan pengguna terhadap website tidak dapat dilepaskan dengan ilmu interaksi manusia dan komputer.

Spesimen yang dijadikan objek penelitian mempunyai karakteristik visual yang berbeda-beda namun dengan fungsi website yang sama yaitu content artikel yang membahas informasi pendidikan dan anak baik yang menggunakan bahasa indonesia atau berbahasa asing, dengan syarat tambahan yang lebih spesifik yaitu dapat diakses melalui mobile browser.
Pendahulu Kansei Engineering yang berfokus kepada bagaimana memahami keinginan konsumen seperti metode Quality Function Deployment, Conjoint Analysis. Metode-metode tersebut mempunyai tujuan yang sama seperti Kansei Engineering yaitu merancang produk sesuai dengan kebutuhan emosi pengguna[1]. Namun Kansei Engineering lebih mengutamakan faktor kenyamanan pengguna dalam mengoperasikan website yang dirancang. sehingga memaksa para programmer untuk dapat memenuhi kebutuhan kenyamanan pengguna disamping fungsionalitas website sehingga produk atau website yang dibangun mempunyai ciri khas karakter tertentu.

Dalam upaya meningkatkan kualitas website yang menyajikan informasi berkaitan dengan tema pendidikan dan anak maka selain fokus kepada isi informasi dari website itu sendiri, dibutuhkan juga perancangan 
tampilan website yang menarik sehingga dapat mengundang minat para pengunjung website. Sehingga media informasi berbasis web dapat dengan mudah dikunjungi oleh penggina umum.

\subsection{Tujuan Penelitian}

Adapun tujuan yang ingin dicapai dalam kegiatan penelitian ini, yaitu :

a. Membuat inovasi alternatif dari faktor analisis yang jika mengikuti tahapan standar dari Kansei Engineering hanya akan menghasilkan satu usulan per kelompok responden.

b. Membuat alternatif usulan terbaru yang lebih dari satu hasil dari asimilasi data faktor analisis menjadi faktor usulan baru.

c. Menghasilkan rekomendasi penggunaan elemen desain tampilan website yang dihasilkan melalui pendekatan statistik multivariate kansei engineering.

\section{Kajian Pustaka}

Sejak tahun 1990an bisnis menggunakan internet dan website sebagai sarana promosi dan transaksi cukup mengalami peningkatan yang signifikan, dalam dunia nyata para pedagang retail sering kali menarik perhatian pembeli dengan merancang toko seindah mungkin, dengan konsep, layout dan presentasi produk yang dapat menarik perhatian pembeli. Dalam industri retail online atau internet dengan adanya ketertarikan pengunjung terhadap website, tergambar dari semakin lamanya waktu seorang pengunjung website beinteraksi terhadap website dan informasi tersebut dapat digambarkan sebagai konsumen potensial.

Hal tersebut menunjukkan bahwa sebuah website belum tentu dapat menangkap keinginan pengunjung dalam pandangan pertama, Maka hal penting yang harus diperhatikan para perancang website adalah bagaimana membuat para pengunjung merasa betah berinteraksi dalam waktu yang lama dengan website yang dibangun.

\subsection{Kansei Engineering.}

Kansei merupakan istilah bahasa Jepang yang digunakan untuk mengekspresikan kesan seseorang terhadap artifak, situasi dan lingkungan sekitarnya. Dengan berakar kuat pada budaya Jepang, terjemahan langsung bahasa Kanseito agak sulit. Memiliki berbagai interpretasi dengan berbagai literatur, Kansei umumnya mengacu pada sensitivitas, kepekaan, perasaan dan emosi [1] [2].

Penelitian menggunakan Kansei melibatkan kepekaan, presisi, perasaan dan emosi yang diselaraskan melalui 5 (lima) indera; penglihatan, pendengaran, penciuman, rasa serta sensasi kulit. Istilah kansei kemudian diterjemahkan ke dalam metode teknik yang disebut kansei engineering [3] [4] [5].

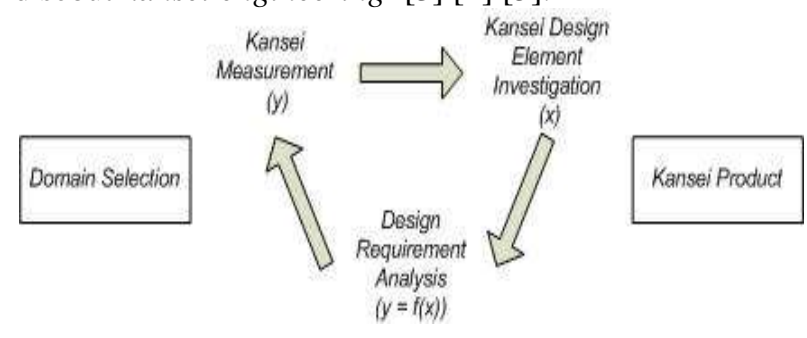

\section{Gambar 1. Prinsip implementasi kansei engineering[6].}

Pada gambar 1 dijelaskan prinsip implementasi kansei engineering yang mungkin terjadi pada semua siklus pengembangan untuk berbagai jenis produk. Prosedur ini mencakup beberapa tahap: pemilihan domain, pengukuran kansei, investigasi elemen desain kansei, dan analisis, untuk pengembangan produk kansei.

\subsection{Analisis Multivariat \\ 2.2.1 Cronbach's Alpha}

Analisis Cronbach's Alpha yang berfungsi untuk mengukur tingkat reliabilitas data secara umum dengan pemisahan parameter responden menurut jenis kelamin, adapun para responden yang terlibat dalam pengisian kuesioner, namun menurut parameter kansei engineering dapat menggunakan responden sekitar 30 hingga 40 orang dalam sebuah penelitian [1].

\subsubsection{Correlation Coeficient Analysis (CCA)}

Correlation adalah teknik analisis untuk menyelidiki hubungan antara dua variabel kuantitatif yang berkelanjutan, misal usia dan tekanan darah. Pearson's Correlation Coeficient ( $\mathrm{r}$ ) adalah ukuran kekuatan hubungan antara dua variabel. Koefisien korelasi ( $\mathrm{r}$ dinotasikan) adalah statistik yang mengukur hubungan antara X dan Y dalam unit yang bebas. Ketika semua titik dari scatter plot jatuh langsung pada garis dengan kemiringan ke atas, $\mathrm{r}=+1$; Ketika semua titik jatuh langsung di lereng bawah, $r=-1$ [10].

\subsubsection{Principal Component Analysis (PCA)}

Dalam ilmu statistika, analisis komponen utama (Principal Component Analysis) adalah teknik yang digunakan untuk menyederhanakan suatu data dengan cara melakukan transformasi linier sehingga terbentuk sistem koordinat baru dengan varians maksimum. PCA dapat digunakan untuk mereduksi dimensi suatu data tanpa mengurangi karakteristik data tersebut secara signifikan [7][8].

\subsubsection{Factor Analysis (FA)}

Fungsi utama teknik factor analysis adalah; 1) untuk mengurangi jumlah variabel dan 2) untuk mendeteksi struktur dalam hubungan antara variabel, yaitu untuk mengklasifikasikan variabel. Oleh karena itu, analisis faktor diterapkan sebagai metode deteksi reduksi data atau struktur, teknik analisis faktor jangka pertama kali diperkenalkan oleh Thurstone pada tahun 1931. Topik yang tercantum di bawah ini akan menjelaskan prinsipprinsip analisis faktor dan bagaimana hal itu dapat diterapkan terhadap dua tujuan tersebut.

Dalam studi perilaku dan sosial, peneliti membutuhkan pengembangan pengukuran untuk bermacam-macam variabel yang tidak dapat diukur secara langsung, seperti tingkah laku, pendapat, intelegensi, personality dan lain-lain. Faktor analisis adalah metode yang dapat digunakan untuk pengukuran semacam itu.[9]. 
Arief Ginanjar ${ }^{1}$ Wahyu Purnama Sari ${ }^{2}$ Herlina $^{3}$, Inovasi Alternatif Perancangan Tampilan Website

Berdasarkan Analisis Faktor Multivariat sebagai Bagian dari Implementasi Kansei Engineering

\subsubsection{Partial Least Square (PLS) Analysis}

Metode ini cepat, efisien dan optimal untuk kriteria berdasarkan variances. Disarankan dalam kasus dimana jumlah variabel yang tinggi dan dimana ada kemungkinan bahwa variabel penjelas berkorelasi.

Dijelaskan bahwa PLS merupakan metode analisis yang powerful karena dapat diterapkan pada semua skala data, tidak membutuhkan banyak asumsi dan ukuran sampel tidak harus besar. PLS selain dapat digunakan sebagai konfirmasi teori juga dapat digunakan untuk membangun hubungan yang belum ada landasan teorinya atau untuk pengujian proposisi. PLS juga dapat digunakan untuk pemodelan struktural dengan indikator bersifat reflektif maupun formatif [11].

\section{Proses Penelitian}

Proses awal dalam penelitian ini dimulai dengan metode menentukan spesimen serta elemen website yang akan dinilai dan dijadikan referensi dari masing-masing spesimen, kemudian menentukan kansei words yang diperkirakan mempunyai korelasi dengan setiap spesimen serta pengumpulan kuisioner yang disebar terhadap responden dengan kriteria yang sudah ditentukan diawal penelitian [12].

Adapun elemen website yang dijadikan faktor penilaian yang berpengaruh terhadap penelitian implementasi kansei engineering ini dapat terlihat pada Tabel 1.

Tabel 1. Referensi Elemen Website

\begin{tabular}{|c|l|l|}
\hline No & Elemen Induk & \multicolumn{1}{|c|}{ Elemen Anak } \\
\hline 1 & Body & Font Size \\
\hline 2 & Body & Font Color \\
\hline 3 & Body & Background Color \\
\hline 4 & Body & Background Style \\
\hline 5 & Top Menu & Existance \\
\hline 6 & Top Menu & Style \\
\hline 7 & Top Menu & Position \\
\hline 8 & Top Menu & Background Color \\
\hline 9 & Top Menu & Font Color \\
\hline 10 & Top Menu & Font Size \\
\hline 11 & Left Menu & Existance \\
\hline 12 & Left Menu & Style \\
\hline 13 & Left Menu & Position \\
\hline 14 & Left Menu & Background Color \\
\hline 15 & Left Menu & Font Color \\
\hline 16 & Left Menu & Font Size \\
\hline 17 & Header & Logo \\
\hline 18 & Header & Background Color \\
\hline 19 & Header & Font Color \\
\hline 20 & Header & Font Size \\
\hline & & \\
\hline
\end{tabular}

\begin{tabular}{|c|l|l|}
\hline No & Elemen Induk & \multicolumn{1}{|c|}{ Elemen Anak } \\
\hline 21 & Footer & Logo \\
\hline 22 & Footer & Background Color \\
\hline 23 & Footer & Font Color \\
\hline 24 & Footer & Font Size \\
\hline
\end{tabular}

Dari elemen website yang akan dilihat sebagai referensi kemudian dilakukan pengumpulan data kuisioner dari para responden diolah menggunakan Semantic Differential dengan struktur yang terlihat pada Tabel 2.

Tabel 2. Struktur Semantic Differential

\begin{tabular}{|c|c|c|c|}
\hline Tanggal & : $\quad$ ………........... & $\begin{array}{l}\text { Nomor } \\
\text { Spesimen }\end{array}$ & : \\
\hline Umur & : $\quad$.................... & $\begin{array}{l}\text { Jenis } \\
\text { Kelamin }\end{array}$ & : $\quad \mathrm{L} / \mathrm{P}$ \\
\hline
\end{tabular}

\begin{tabular}{|c|c|c|c|c|c|c|c|}
\hline No & Kansei Words & & kor & en & ian & & Kansei Words \\
\hline 1 & Menarik & 5 & 4 & 3 & 2 & 1 & Tidak Menarik \\
\hline 2 & Tenang & 5 & 4 & 3 & 2 & 1 & Tidak Tenang \\
\hline 3 & $\begin{array}{l}\text { Kekanan- } \\
\text { kanakan }\end{array}$ & 5 & 4 & 3 & 2 & 1 & $\begin{array}{l}\text { Tidak Kekanan- } \\
\text { kanakan }\end{array}$ \\
\hline 4 & Klasik & 5 & 4 & 3 & 2 & 1 & Tidak Klasik \\
\hline 5 & Nyaman & 5 & 4 & 3 & 2 & 1 & Tidak Nyaman \\
\hline 6 & Keren & 5 & 4 & 3 & 2 & 1 & Tidak Keren \\
\hline 7 & Kreatif & 5 & 4 & 3 & 2 & 1 & Tidak Kreatif \\
\hline 8 & Penuh Sesak & 5 & 4 & 3 & 2 & 1 & $\begin{array}{l}\text { Tidak Penuh } \\
\text { Sesak }\end{array}$ \\
\hline 9 & Lucu & 5 & 4 & 3 & 2 & 1 & Tidak Lucu \\
\hline 10 & Anggun & 5 & 4 & 3 & 2 & 1 & Tidak Anggun \\
\hline 11 & Feminin & 5 & 4 & 3 & 2 & 1 & Tidak Feminin \\
\hline 12 & Indah & 5 & 4 & 3 & 2 & 1 & Tidak Indah \\
\hline 13 & Impresif & 5 & 4 & 3 & 2 & 1 & Tidak Impresif \\
\hline 14 & Lebih Hidup & 5 & 4 & 3 & 2 & 1 & $\begin{array}{l}\text { Tidak Lebih } \\
\text { Hidup }\end{array}$ \\
\hline 15 & Mewah & 5 & 4 & 3 & 2 & 1 & Tidak Mewah \\
\hline 16 & Alami & 5 & 4 & 3 & 2 & 1 & Tidak Alami \\
\hline 17 & Serasi & 5 & 4 & 3 & 2 & 1 & Tidak Serasi \\
\hline 18 & Biasa & 5 & 4 & 3 & 2 & 1 & Tidak Biasa \\
\hline 19 & Profesional & 5 & 4 & 3 & 2 & 1 & $\begin{array}{l}\text { Tidak } \\
\text { Profesional }\end{array}$ \\
\hline 20 & Sederhana & 5 & 4 & 3 & 2 & 1 & Tidak Sederhana \\
\hline
\end{tabular}




\begin{tabular}{|c|l|c|c|c|c|c|l|}
\hline No & Kansei Words & \multicolumn{5}{|c|}{ Skor Penilaian } & \multicolumn{2}{|c|}{ Kansei Words } \\
\hline 21 & Canggih & 5 & 4 & 3 & 2 & 1 & Tidak Canggih \\
\hline 22 & $\begin{array}{l}\text { Mudah } \\
\text { Digunakan }\end{array}$ & 5 & 4 & 3 & 2 & 1 & $\begin{array}{l}\text { Tidak Mudah } \\
\text { Digunakan }\end{array}$ \\
\hline 23 & Informatif & 5 & 4 & 3 & 2 & 1 & Tidak Informatif \\
\hline 24 & Formal & 5 & 4 & 3 & 2 & 1 & Tidak Formal \\
\hline 25 & Ceria & 5 & 4 & 3 & 2 & 1 & Tidak Ceria \\
\hline 26 & Unik & 5 & 4 & 3 & 2 & 1 & Tidak Unik \\
\hline
\end{tabular}

Kemudian dari tiga sumber data tersebut diolah menggunakan proses analisis multivariat, namun perlu diketahui juga bahwa data populasi dari sebuah objek penelitian dapat diputuskan untuk digunakan jika varietas data populasi dapat mencakup hanya lima data atau bahkan ribuan data tergantung tujuan objek pencarian data serta alat yang digunakan[12].

Maka untuk penelitian ini jumlah responden disarankan cukup antara 30 hingga 50 orang dengan mengisi kuesioner dengan form isian berupa semantic differential. Sehingga dalam penelitian tersebut berhasil mendapatkan responden dengan kelompok umur seperti yang terlihat pada Tabel 3 .

Tabel 3. Kelompok responden menurut umur dan jenis kelamin

\begin{tabular}{|c|c|c|c|c|c|}
\hline \multirow{2}{*}{ No } & \multirow{2}{*}{$\begin{array}{c}\text { Jenis } \\
\text { Kelamin }\end{array}$} & \multicolumn{4}{|c|}{ Kelompok Umur } \\
\cline { 3 - 6 } & $\mathbf{2 0}-\mathbf{3 0}$ & $\mathbf{3 1}-\mathbf{4 0}$ & $\mathbf{4 1}-\mathbf{5 0}$ & $\mathbf{7 5 0}$ \\
\hline 1 & Pria & 5 & 6 & 3 & 4 \\
\hline 2 & Wanita & 9 & 3 & 0 & 0 \\
\hline
\end{tabular}

Seluruh proses analisis statistik multivariat merujuk terhadap data penelitian yang sudah terkumpul sebelumnya sehingga yang perlu dilanjutkan berikutnya adalah mencari inovasi baru dengan mengasimilasi nilai tertinggi dari faktor analisis dan partial least square.

\subsection{Korelasi Data Statistik terhadap Elemen Website.}

Analisis Partial Least Square (PLS) digunakan dalam menterjemahkan data statistik dimana proses perhitungan berasal dari elemen desain berdasarkan kansei words yang saling berkaitan, hasil yang diharapkan dari proses PLS adalah mengetahui elemen dari spesimen tertentu yang mempunyai nilai kecenderungan tertinggi terhadap kansei words [13].

Sebelum masuk dalam proses perhitungan PLS, perlu adanya perubahan data elemen yang sebelumnya berupa centang dan tidak centang menjadi angka satu dan nol hingga dihasilkan sebanyak 65 kolom variabel dummy, data elemen website yang terlihat dalam tabel 4 hanya data parsial yang mewakili kesuluruhan data elemen sebanyak 65 kolom.
Tabel 4. Data elemen website dirubah menjadi variabel dummy.

\begin{tabular}{|c|c|c|c|c|c|c|c|c|c|}
\hline 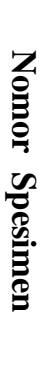 & 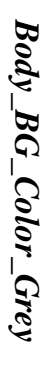 & ָ) & 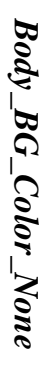 & 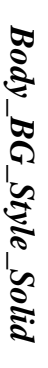 & 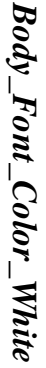 & 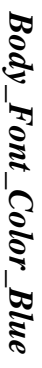 & 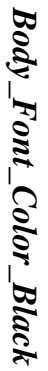 & 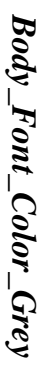 & $\cdots$ \\
\hline 1 & 1 & 0 & 0 & 1 & 1 & 0 & 0 & 0 & $\ldots$ \\
\hline 2 & 0 & 1 & 0 & 1 & 0 & 0 & 0 & 1 & $\ldots$ \\
\hline 3 & 0 & 1 & 0 & 1 & 0 & 0 & 1 & 0 & $\ldots$ \\
\hline 4 & 0 & 1 & 0 & 1 & 0 & 0 & 1 & 0 & $\ldots$ \\
\hline 5 & 0 & 0 & 1 & 0 & 0 & 0 & 1 & 0 & $\ldots$ \\
\hline 6 & 0 & 1 & 0 & 1 & 0 & 1 & 0 & 0 & $\ldots$ \\
\hline 7 & 1 & 0 & 0 & 0 & 0 & 0 & 1 & 0 & $\ldots$ \\
\hline 8 & 0 & 0 & 1 & 0 & 0 & 0 & 1 & 0 & $\ldots$ \\
\hline 9 & 0 & 1 & 0 & 1 & 0 & 0 & 1 & 0 & $\ldots$ \\
\hline 10 & 0 & 1 & 0 & 1 & 0 & 0 & 1 & 0 & $\ldots$ \\
\hline
\end{tabular}

PLS merupakan metode analisis yang handal serta dapat diterapkan dalam berbagai tingkatan skala, kemudian tidak membutuhkan banyak asumsi serta tidak membutuhkan skala data yang besar. PLS dapat dijadikan sebagai alat ukur konfirmasi teori untuk digunakan dalam membangun data yang tidak mempunyai dasar teoritis kuat serta dapat juga digunakan sebagai proposisi teori[10].

Dalam proses penelitian ini data hasil dari proses principal component analysis dan factor analysis digabungkan dengan kansei words untuk mendapatkan nilai elemen desain website yang dapat digunakan sebagai rujukan untuk proses PLS. Tujuan utama dari proses analisis tersebut merupakan untuk mengetahui elemen website yang paling mempengaruhi perasaan responden [13]. Rujukan tersebut dapat terlihat pada tabel 5.

Tabel 5. Hasil PLS untuk mencari nilai tertinggi komponen website untuk responden pria dengan kansei word 'Mudah Digunakan'.

\begin{tabular}{|c|c|c|c|c|}
\hline \multirow{3}{*}{ No } & \multirow{1}{*}{ Kategori } & \multicolumn{2}{|c|}{ Mudah Digunakan } & Range \\
\cline { 3 - 4 } & & Variabel & Coeff & $\mathbf{0 . 0 5 8}$ \\
\hline \multirow{3}{*}{1} & $\begin{array}{l}\text { Footer BG } \\
\text { Color Blue }\end{array}$ & 0.022 & \\
\cline { 3 - 4 } & $\begin{array}{c}\text { Footer } \\
\text { Cologround }\end{array}$ & $\begin{array}{l}\text { Footer BG } \\
\text { Color Grey }\end{array}$ & 0.053 & \\
\cline { 3 - 4 } & $\begin{array}{l}\text { Footer BG } \\
\text { Color White }\end{array}$ & 0.020 & \multirow{2}{*}{0.160} \\
\cline { 3 - 4 } & & $\begin{array}{l}\text { Footer BG } \\
\text { Color Black }\end{array}$ & -0.107 & \\
\cline { 3 - 4 } & & $\begin{array}{l}\text { Footer BG } \\
\text { Color None }\end{array}$ & 0.012 & \\
\hline
\end{tabular}


Arief Ginanjar ${ }^{1}$ Wahyu Purnama Sari ${ }^{2}$ Herlina $^{3}$, Inovasi Alternatif Perancangan Tampilan Website Berdasarkan Analisis Faktor Multivariat sebagai Bagian dari Implementasi Kansei Engineering

\begin{tabular}{|c|c|c|c|c|}
\hline \multirow{2}{*}{ No } & \multirow{2}{*}{ Kategori } & \multicolumn{2}{|c|}{ Mudah Digunakan } & \multirow{2}{*}{$\frac{\text { Range }}{0.058}$} \\
\hline & & Variabel & Coeff & \\
\hline \multirow{2}{*}{2} & \multirow{2}{*}{$\begin{array}{c}\text { Header Font } \\
\text { Size }\end{array}$} & $\begin{array}{l}\text { Header } \\
\text { Font Size } \\
\text { Small }\end{array}$ & 0.066 & \multirow{2}{*}{0.132} \\
\hline & & $\begin{array}{l}\text { Header } \\
\text { Font Size } \\
\text { Medium }\end{array}$ & -0.066 & \\
\hline \multirow{5}{*}{3} & \multirow{5}{*}{$\begin{array}{c}\text { Header Font } \\
\text { Color }\end{array}$} & $\begin{array}{l}\text { Header } \\
\text { Font Color } \\
\text { White }\end{array}$ & 0.055 & \multirow{5}{*}{0.118} \\
\hline & & $\begin{array}{l}\text { Header } \\
\text { Font Color } \\
\text { Blue }\end{array}$ & 0.020 & \\
\hline & & $\begin{array}{l}\text { Header } \\
\text { Font Color } \\
\text { Purple }\end{array}$ & 0.060 & \\
\hline & & $\begin{array}{l}\text { Header } \\
\text { Font Color } \\
\text { Black }\end{array}$ & -0.058 & \\
\hline & & $\begin{array}{l}\text { Header } \\
\text { Font Color } \\
\text { Grey }\end{array}$ & -0.038 & \\
\hline \multirow{5}{*}{4} & \multirow{5}{*}{$\begin{array}{l}\text { Footer Font } \\
\text { Color }\end{array}$} & $\begin{array}{l}\text { Footer Font } \\
\text { Color White }\end{array}$ & 0.001 & \multirow{5}{*}{0.106} \\
\hline & & $\begin{array}{l}\text { Footer Font } \\
\text { Color Blue }\end{array}$ & -0.046 & \\
\hline & & $\begin{array}{l}\text { Footer Font } \\
\text { Color Black }\end{array}$ & 0.012 & \\
\hline & & $\begin{array}{l}\text { Footer Font } \\
\text { Color } \\
\text { Green }\end{array}$ & 0.060 & \\
\hline & & $\begin{array}{l}\text { Footer Font } \\
\text { Color Grey }\end{array}$ & -0.038 & \\
\hline \multirow{3}{*}{5} & \multirow{3}{*}{$\begin{array}{l}\text { Top Menu } \\
\text { Position }\end{array}$} & $\begin{array}{l}\text { Top Menu } \\
\text { Position } \\
\text { Left }\end{array}$ & -0.050 & \multirow{3}{*}{0.106} \\
\hline & & $\begin{array}{l}\text { Top Menu } \\
\text { Position } \\
\text { Center } \\
\end{array}$ & -0.010 & \\
\hline & & $\begin{array}{l}\text { Top Menu } \\
\text { Position } \\
\text { Right }\end{array}$ & 0.056 & \\
\hline \multirow{3}{*}{6} & \multirow{3}{*}{$\begin{array}{c}\text { Header } \\
\text { Background } \\
\text { Color }\end{array}$} & $\begin{array}{l}\text { Header BG } \\
\text { Color Blue }\end{array}$ & 0.055 & \multirow{3}{*}{0.100} \\
\hline & & $\begin{array}{l}\text { Header BG } \\
\text { Color White }\end{array}$ & -0.045 & \\
\hline & & $\begin{array}{l}\text { Header BG } \\
\text { Color None }\end{array}$ & 0.012 & \\
\hline \multirow[b]{2}{*}{7} & \multirow[b]{2}{*}{$\begin{array}{l}\text { Body Font } \\
\text { Size }\end{array}$} & $\begin{array}{l}\text { Body Font } \\
\text { Size Small }\end{array}$ & -0.050 & \multirow[b]{2}{*}{0.099} \\
\hline & & $\begin{array}{l}\text { Body Font } \\
\text { Size } \\
\text { Medium } \\
\end{array}$ & 0.050 & \\
\hline \multirow{2}{*}{8} & \multirow{2}{*}{$\begin{array}{c}\text { Top Menu } \\
\text { Background } \\
\text { Color }\end{array}$} & $\begin{array}{ll}\text { Top } & \text { Menu } \\
\text { BG } & \text { Color } \\
\text { Blue } & \\
\end{array}$ & -0.023 & \multirow{2}{*}{0.091} \\
\hline & & $\begin{array}{ll}\text { Top } & \text { Menu } \\
\text { BG } & \text { Color } \\
\text { Grey } & \\
\end{array}$ & -0.024 & \\
\hline
\end{tabular}

\begin{tabular}{|c|c|c|c|c|}
\hline \multirow{4}{*}{ No } & \multirow{4}{*}{ Kategori } & \multicolumn{2}{|c|}{ Mudah Digunakan } & \multirow{2}{*}{$\frac{\text { Range }}{0.058}$} \\
\hline & & Variabel & \multirow{2}{*}{$\begin{array}{c}\text { Coeff } \\
0.028\end{array}$} & \\
\hline & & $\begin{array}{ll}\text { Top } & \text { Menu } \\
\text { BG } & \text { Color } \\
\text { White } & \end{array}$ & & \\
\hline & & $\begin{array}{ll}\text { Top } & \text { Menu } \\
\text { BG } & \text { Color } \\
\text { None } & \\
\end{array}$ & 0.068 & \\
\hline \multirow[b]{2}{*}{9} & \multirow[b]{2}{*}{$\begin{array}{c}\text { Footer Font } \\
\text { Size }\end{array}$} & $\begin{array}{l}\text { Footer Font } \\
\text { Size Small }\end{array}$ & -0.045 & \multirow[b]{2}{*}{0.090} \\
\hline & & $\begin{array}{l}\text { Footer Font } \\
\text { Size } \\
\text { Medium }\end{array}$ & 0.045 & \\
\hline \multirow{4}{*}{10} & \multirow{4}{*}{$\begin{array}{l}\text { Body Font } \\
\quad \text { Color }\end{array}$} & $\begin{array}{l}\text { Body Font } \\
\text { Color White }\end{array}$ & 0.050 & \multirow{4}{*}{0.086} \\
\hline & & $\begin{array}{l}\text { Body Font } \\
\text { Color Blue }\end{array}$ & -0.010 & \\
\hline & & $\begin{array}{l}\text { Body Font } \\
\text { Color Black }\end{array}$ & -0.036 & \\
\hline & & $\begin{array}{l}\text { Body Font } \\
\text { Color Grey }\end{array}$ & 0.045 & \\
\hline \multirow{4}{*}{11} & \multirow{4}{*}{$\begin{array}{l}\text { Top Menu } \\
\text { Font Color }\end{array}$} & $\begin{array}{ll}\text { Top Menu } \\
\text { Font Color } \\
\text { White }\end{array}$ & -0.023 & \multirow{4}{*}{0.082} \\
\hline & & $\begin{array}{ll}\text { Top } & \text { Menu } \\
\text { Font } & \text { Color } \\
\text { Blue } & \\
\end{array}$ & -0.005 & \\
\hline & & $\begin{array}{ll}\text { Top } & \text { Menu } \\
\text { Font } & \text { Color } \\
\text { Black } & \\
\end{array}$ & 0.044 & \\
\hline & & $\begin{array}{ll}\text { Top } & \text { Menu } \\
\text { Font } & \text { Color } \\
\text { Grey } & \\
\end{array}$ & -0.038 & \\
\hline \multirow{2}{*}{12} & \multirow{2}{*}{$\begin{array}{l}\text { Top Menu } \\
\text { Font Size }\end{array}$} & $\begin{array}{lr}\text { Top } & \text { Menu } \\
\text { Font } & \text { Size } \\
\text { Small } & \\
\end{array}$ & -0.030 & \multirow{2}{*}{0.060} \\
\hline & & $\begin{array}{l}\text { Top Menu } \\
\text { Font Size } \\
\text { Medium }\end{array}$ & 0.030 & \\
\hline
\end{tabular}

Setelah nilai range dari masing-masing kategori didapatkan maka langkah selanjutnya adalah mencari nilai rata-rata seluruh range dalam satu kelompok kansei words. Sehingga dalam sebuah kansei words didapatkan nilai range yang akan dijadian acuan dalam tingkatan pengaruh setiap kategori terhadap konsep kansei words. Bila nilai range dari suatu kategori lebih rendah dari nilai patokan range tersebut maka kategori dengan nilai range rendah tidak akan berpengaruh dalam konsep kansei words sehingga kategori tersebut dapat dihapus. Seperti yang terlihat pada Tabel 5 terlihat kansei words 'Mudah Digunakan' dengan nilai acuan range sebesar 0.058 .

Setelah mendapatkan nilai patokan range dari ratarata range untuk setiap kategori maka dapat terlihat nilai range kategori yang memiliki nilai lebih tinggi dan lebih rendah dari nilai rata-rata range. Dari data fakta tersebut maka dapat dipastikan kategori yang mempunyai nilai range lebih rendah dari nilai rata-rata range akan diabaikan. 
Langkah selanjutnya adalah lakukan pengurutan data mulai dari range terbesar hingga range terkecil untuk masing-masing kansei words dari data yang berasal seluruh responden, responden pria dan responden wanita untuk kansei words yang tertinggi saja kemudian abaikan kategori yang mempunyai nilai range lebih kecil dari nilai rata-rata range, maka hasil dari sorting tersebut akan terlihat pada Tabel 6.

Tabel 6. Kategori dan nilai range setelah diurut.

\begin{tabular}{|c|c|c|c|c|}
\hline \multirow{3}{*}{ No } & \multicolumn{2}{|c|}{ Nyaman } & \multicolumn{2}{|c|}{ Mudah Digunakan } \\
\hline & \multirow{2}{*}{ Kategori } & Range & \multirow{2}{*}{ Kategori } & Range \\
\hline & & 0.078 & & 0.058 \\
\hline 1 & $\begin{array}{l}\text { Body Font } \\
\text { Size }\end{array}$ & 0.220 & $\begin{array}{l}\text { Footer } \\
\text { Backgroun } \\
d \text { Color }\end{array}$ & 0.160 \\
\hline 2 & $\begin{array}{l}\text { Body Font } \\
\text { Color }\end{array}$ & 0.187 & $\begin{array}{l}\text { Header } \\
\text { Font Size }\end{array}$ & 0.132 \\
\hline 3 & $\begin{array}{l}\text { Footer } \\
\text { Backgrou } \\
\text { nd Color }\end{array}$ & 0.156 & $\begin{array}{l}\text { Header } \\
\text { Font Color }\end{array}$ & 0.118 \\
\hline 4 & $\begin{array}{l}\text { Top Mепи } \\
\text { Position }\end{array}$ & 0.149 & $\begin{array}{l}\text { Footer } \\
\text { Font Color }\end{array}$ & 0.106 \\
\hline 5 & $\begin{array}{l}\text { Footer } \\
\text { Font } \\
\text { Color }\end{array}$ & 0.141 & $\begin{array}{l}\text { Top Menu } \\
\text { Position }\end{array}$ & 0.106 \\
\hline 6 & $\begin{array}{l}\text { Footer } \\
\text { Font Size }\end{array}$ & 0.129 & $\begin{array}{l}\text { Header } \\
\text { Backgroun } \\
d \text { Color }\end{array}$ & 0.100 \\
\hline 7 & $\begin{array}{l}\text { Header } \\
\text { Font } \\
\text { Color }\end{array}$ & 0.113 & $\begin{array}{l}\text { Body Font } \\
\text { Size }\end{array}$ & 0.099 \\
\hline 8 & $\begin{array}{l}\text { Top Menu } \\
\text { Font } \\
\text { Color }\end{array}$ & 0.112 & $\begin{array}{l}\text { Top Menu } \\
\text { Backgroun } \\
\text { d Color }\end{array}$ & 0.091 \\
\hline 9 & $\begin{array}{l}\text { Body } \\
\text { Backgrou } \\
\text { nd Color }\end{array}$ & 0.109 & $\begin{array}{l}\text { Footer } \\
\text { Font Size }\end{array}$ & 0.090 \\
\hline 10 & $\begin{array}{l}\text { Header } \\
\text { Font Size }\end{array}$ & 0.107 & $\begin{array}{l}\text { Body Font } \\
\text { Color }\end{array}$ & 0.086 \\
\hline 11 & $\begin{array}{l}\text { Footer } \\
\text { Logo } \\
\text { Position }\end{array}$ & 0.098 & $\begin{array}{l}\text { Top Menu } \\
\text { Font Color }\end{array}$ & 0.082 \\
\hline 12 & $\begin{array}{l}\text { Top Мenu } \\
\text { Backgrou } \\
\text { nd Color }\end{array}$ & 0.092 & $\begin{array}{l}\text { Top Мепи } \\
\text { Font Size }\end{array}$ & 0.060 \\
\hline 13 & $\begin{array}{l}\text { Left Menu } \\
\text { Backgrou } \\
\text { nd Color }\end{array}$ & 0.068 & $\begin{array}{l}\text { Body } \\
\text { Backgroun } \\
d \text { Color }\end{array}$ & 0.032 \\
\hline 14 & $\begin{array}{l}\text { Left Menu } \\
\text { Font } \\
\text { Color }\end{array}$ & 0.068 & $\begin{array}{l}\text { Left Menu } \\
\text { Backgroun } \\
d \text { Color }\end{array}$ & 0.028 \\
\hline 15 & $\begin{array}{l}\text { Left Menu } \\
\text { Font Size }\end{array}$ & 0.042 & $\begin{array}{l}\text { Left Menu } \\
\text { Font Color }\end{array}$ & 0.028 \\
\hline 16 & $\begin{array}{l}\text { Header } \\
\text { Backgrou } \\
\text { nd Color }\end{array}$ & 0.032 & $\begin{array}{l}\text { Left Menu } \\
\text { Style }\end{array}$ & 0.025 \\
\hline 17 & $\begin{array}{l}\text { Left Menu } \\
\text { Style }\end{array}$ & 0.028 & $\begin{array}{l}\text { Footer Logo } \\
\text { Position }\end{array}$ & 0.020 \\
\hline 18 & Тор Мепи & 0.011 & Тор Мепи & 0.020 \\
\hline
\end{tabular}

\begin{tabular}{|c|c|c|c|c|}
\hline \multirow{3}{*}{ No } & \multicolumn{2}{|c|}{ Nyaman } & \multicolumn{2}{|c|}{ Mudah Digunakan } \\
\hline & \multirow{2}{*}{ Kategori } & Range & \multirow{2}{*}{ Kategori } & Range \\
\hline & & 0.078 & & 0.058 \\
\hline & Style & & Style & \\
\hline 19 & $\begin{array}{l}\text { Header } \\
\text { Logo } \\
\text { Position } \\
\end{array}$ & 0.009 & $\begin{array}{l}\text { Header } \\
\text { Logo } \\
\text { Position } \\
\end{array}$ & 0.004 \\
\hline 20 & $\begin{array}{l}\text { Top Menu } \\
\text { Font Size }\end{array}$ & 0.006 & $\begin{array}{l}\text { Left Menu } \\
\text { Font Size }\end{array}$ & 0.003 \\
\hline 21 & $\begin{array}{l}\text { Body } \\
\text { Backgrou } \\
\text { nd Style } \\
\end{array}$ & 0.005 & $\begin{array}{l}\text { Body } \\
\text { Backgroun } \\
\text { d Style }\end{array}$ & 0.002 \\
\hline
\end{tabular}

\subsection{Matrik Usulan Analisis}

Tahap selanjutnya adalah membuat rekomendasi konsep desain tampilan berdasarkan hasil perhitungan PLS dengan membuat matriks rekomendasi konsep desain tampilan. Elemen desain yang memiliki nilai range diatas nilai rata-rata range akan digunakan seluruhnya untuk rekomendasi. Elemen-elemen desain tersebut berdasarkan hasil analisis dapat memberikan pengaruh kansei words terhadap pengguna website. Seperti yang telah diketahui sebelumnya dari proses FA menghasilkan rekomendasi kansei words yang terwakili dalam kansei words tertinggi 'Nyaman' dari data seluruh responden, 'Mudah Digunakan' dari data responden pria dan 'Kreatif' dari data responden wanita.

Kansei words tersebut akan menjadi referensi dalam perancangan usulan matriks, selanjutnya proses penyusunan matriks usulan website artikel anak akan dilakukan dengan cara manual menggunakan hasil analisis PLS dimana data kategori yang sudah diurut berdasarkan nilai range paling besar hingga paling kecil dengan tujuan dapat diketahui nilai range yang lebih besar dari nilai rata-rata range [10] seperti yang terlihat pada Tabel 6 kemudian akan digabungkan kembali dengan data PLS yang mempunyai data coefficient.

Tabel 7. Pengolahan hasil PLS untuk mencari nilai variabel paling tinggi terhadap kansei words 'Mudah Digunakan'.

\begin{tabular}{|c|c|c|c|c|}
\hline \multirow{2}{*}{ No } & \multirow{2}{*}{ Kategori } & \multicolumn{2}{|c|}{ Mudah Digunakan } & Range \\
\hline & & Variabel & Coeff & 0.058 \\
\hline \multirow{5}{*}{1} & \multirow{5}{*}{$\begin{array}{c}\text { Footer } \\
\text { Background } \\
\text { Color }\end{array}$} & $\begin{array}{l}\text { Footer BG } \\
\text { Color Blue }\end{array}$ & 0.022 & \multirow{5}{*}{0.160} \\
\hline & & $\begin{array}{l}\text { Footer BG } \\
\text { Color Grey }\end{array}$ & 0.053 & \\
\hline & & $\begin{array}{l}\text { Footer BG } \\
\text { Color White }\end{array}$ & 0.020 & \\
\hline & & $\begin{array}{l}\text { Footer BG } \\
\text { Color Black }\end{array}$ & -0.107 & \\
\hline & & $\begin{array}{l}\text { Footer BG } \\
\text { Color None }\end{array}$ & 0.012 & \\
\hline \multirow{2}{*}{2} & \multirow{2}{*}{$\begin{array}{c}\text { Header Font } \\
\text { Size }\end{array}$} & $\begin{array}{l}\text { Header } \\
\text { Font Size } \\
\text { Small }\end{array}$ & 0.066 & \multirow{2}{*}{0.132} \\
\hline & & $\begin{array}{l}\text { Header } \\
\text { Font Size } \\
\text { Medium }\end{array}$ & -0.066 & \\
\hline
\end{tabular}


Arief Ginanjar ${ }^{1}$ Wahyu Purnama Sari ${ }^{2}$ Herlina $^{3}$, Inovasi Alternatif Perancangan Tampilan Website

Berdasarkan Analisis Faktor Multivariat sebagai Bagian dari Implementasi Kansei Engineering

\begin{tabular}{|c|c|c|c|c|}
\hline \multirow{2}{*}{ No } & \multirow{2}{*}{ Kategori } & \multicolumn{2}{|c|}{ Mudah Digunakan } & \multirow{2}{*}{$\frac{\text { Range }}{0.058}$} \\
\hline & & Variabel & Coeff & \\
\hline \multirow{5}{*}{3} & \multirow{5}{*}{$\begin{array}{c}\text { Header Font } \\
\text { Color }\end{array}$} & $\begin{array}{l}\text { Header } \\
\text { Font Color } \\
\text { White }\end{array}$ & 0.055 & \multirow{5}{*}{0.118} \\
\hline & & $\begin{array}{l}\text { Header } \\
\text { Font Color } \\
\text { Blue }\end{array}$ & 0.020 & \\
\hline & & $\begin{array}{l}\text { Header } \\
\text { Font Color } \\
\text { Purple }\end{array}$ & 0.060 & \\
\hline & & $\begin{array}{l}\text { Header } \\
\text { Font Color } \\
\text { Black }\end{array}$ & -0.058 & \\
\hline & & $\begin{array}{l}\text { Header } \\
\text { Font Color } \\
\text { Grey }\end{array}$ & -0.038 & \\
\hline \multirow{5}{*}{4} & \multirow{5}{*}{$\begin{array}{l}\text { Footer Font } \\
\text { Color }\end{array}$} & $\begin{array}{l}\text { Footer Font } \\
\text { Color White }\end{array}$ & 0.001 & \multirow{5}{*}{0.106} \\
\hline & & $\begin{array}{l}\text { Footer Font } \\
\text { Color Blue }\end{array}$ & -0.046 & \\
\hline & & $\begin{array}{l}\text { Footer Font } \\
\text { Color Black }\end{array}$ & 0.012 & \\
\hline & & $\begin{array}{l}\text { Footer Font } \\
\text { Color } \\
\text { Green }\end{array}$ & 0.060 & \\
\hline & & $\begin{array}{l}\text { Footer Font } \\
\text { Color Grey }\end{array}$ & -0.038 & \\
\hline \multirow{3}{*}{5} & \multirow{3}{*}{$\begin{array}{l}\text { Top Menu } \\
\text { Position }\end{array}$} & $\begin{array}{l}\text { Top Menu } \\
\text { Position } \\
\text { Left }\end{array}$ & -0.050 & \multirow{3}{*}{0.106} \\
\hline & & $\begin{array}{l}\text { Top Menu } \\
\text { Position } \\
\text { Center }\end{array}$ & -0.010 & \\
\hline & & $\begin{array}{l}\text { Top Menu } \\
\text { Position } \\
\text { Right } \\
\end{array}$ & 0.056 & \\
\hline \multirow{3}{*}{6} & \multirow{3}{*}{$\begin{array}{c}\text { Header } \\
\text { Background } \\
\text { Color }\end{array}$} & $\begin{array}{l}\text { Header BG } \\
\text { Color Blue }\end{array}$ & 0.055 & \multirow{3}{*}{0.100} \\
\hline & & $\begin{array}{l}\text { Header BG } \\
\text { Color White }\end{array}$ & -0.045 & \\
\hline & & $\begin{array}{l}\text { Header BG } \\
\text { Color None }\end{array}$ & 0.012 & \\
\hline \multirow[b]{2}{*}{7} & \multirow[b]{2}{*}{$\begin{array}{l}\text { Body Font } \\
\text { Size }\end{array}$} & $\begin{array}{l}\text { Body Font } \\
\text { Size Small }\end{array}$ & -0.050 & \multirow[b]{2}{*}{0.099} \\
\hline & & $\begin{array}{l}\text { Body Font } \\
\text { Size } \\
\text { Medium }\end{array}$ & 0.050 & \\
\hline \multirow{4}{*}{8} & \multirow{4}{*}{$\begin{array}{c}\text { Top Menu } \\
\text { Background } \\
\text { Color }\end{array}$} & $\begin{array}{ll}\text { Top } & \text { Menu } \\
\text { BG } & \text { Color } \\
\text { Blue } & \\
\end{array}$ & -0.023 & \multirow{4}{*}{0.091} \\
\hline & & $\begin{array}{ll}\text { Top } & \text { Menu } \\
\text { BG } & \text { Color } \\
\text { Grey } & \\
\end{array}$ & -0.024 & \\
\hline & & $\begin{array}{ll}\text { Top } & \text { Menu } \\
\text { BG } & \text { Color } \\
\text { White } & \\
\end{array}$ & 0.028 & \\
\hline & & $\begin{array}{ll}\text { Top } & \text { Menu } \\
\text { BG } & \text { Color } \\
\text { None } & \\
\end{array}$ & 0.068 & \\
\hline
\end{tabular}

\begin{tabular}{|c|c|c|c|c|}
\hline \multirow{2}{*}{ No } & \multirow{2}{*}{ Kategori } & \multicolumn{2}{|c|}{ Mudah Digunakan } & \multirow{2}{*}{$\frac{\text { Range }}{0.058}$} \\
\hline & & Variabel & Coeff & \\
\hline \multirow[b]{2}{*}{9} & \multirow{2}{*}{$\begin{array}{c}\text { Footer Font } \\
\text { Size }\end{array}$} & $\begin{array}{l}\text { Footer Font } \\
\text { Size Small }\end{array}$ & -0.045 & \multirow[b]{2}{*}{0.090} \\
\hline & & $\begin{array}{l}\text { Footer Font } \\
\text { Size } \\
\text { Medium }\end{array}$ & 0.045 & \\
\hline \multirow{4}{*}{10} & \multirow{4}{*}{$\begin{array}{l}\text { Body Font } \\
\quad \text { Color }\end{array}$} & $\begin{array}{l}\text { Body Font } \\
\text { Color White }\end{array}$ & 0.050 & \multirow{4}{*}{0.086} \\
\hline & & $\begin{array}{l}\text { Body Font } \\
\text { Color Blue }\end{array}$ & -0.010 & \\
\hline & & $\begin{array}{l}\text { Body Font } \\
\text { Color Black }\end{array}$ & -0.036 & \\
\hline & & $\begin{array}{l}\text { Body Font } \\
\text { Color Grey }\end{array}$ & 0.045 & \\
\hline \multirow{4}{*}{11} & \multirow{4}{*}{$\begin{array}{l}\text { Top Menu } \\
\text { Font Color }\end{array}$} & $\begin{array}{ll}\text { Top Menu } \\
\text { Font Color } \\
\text { White }\end{array}$ & -0.023 & \multirow{4}{*}{0.082} \\
\hline & & $\begin{array}{ll}\text { Top } & \text { Menu } \\
\text { Font } & \text { Color } \\
\text { Blue } & \\
\end{array}$ & -0.005 & \\
\hline & & $\begin{array}{ll}\text { Top } & \text { Menu } \\
\text { Font } & \text { Color } \\
\text { Black } & \\
\end{array}$ & 0.044 & \\
\hline & & $\begin{array}{ll}\text { Top } & \text { Menu } \\
\text { Font } & \text { Color } \\
\text { Grey } & \\
\end{array}$ & -0.038 & \\
\hline \multirow{2}{*}{12} & \multirow{2}{*}{$\begin{array}{l}\text { Top Mепи } \\
\text { Font Size }\end{array}$} & $\begin{array}{lr}\text { Top } & \text { Menu } \\
\text { Font } & \text { Size } \\
\text { Small } & \\
\end{array}$ & -0.030 & \multirow{2}{*}{0.060} \\
\hline & & $\begin{array}{l}\text { Top Menu } \\
\text { Font Size } \\
\text { Medium }\end{array}$ & 0.030 & \\
\hline
\end{tabular}

Sedangkan untuk data yang terdapat dalam Tabel 8 kategori 'footer background color' dalam kansei words 'Mudah Digunakan' diurut nilai coefficient terbesar dalam kategori tersebut merupakan 'footer background color grey' atau background color berwarna abu-abu dengan nilai 0.053 maka warna abu-abu akan dipilih untuk mewakili kategori footer background color atau warna abu-abu akan digunakan sebagai referensi untuk warna background dalam elemen footer, begitu pula untuk kategori yang lain hanya akan dipilih variabel dengan nilai coefficient tertinggi untuk mewakili masingmasing kategori dalam kansei words 'Mudah Digunakan'.

Tabel 8. Salah satu matriks usulan elemen website untuk kategori 'footer'.

\begin{tabular}{|c|c|c|c|c|c|c|}
\hline \multirow[b]{2}{*}{ No } & \multirow[b]{2}{*}{$\begin{array}{c}\text { Konsep } \\
\text { Desain }\end{array}$} & \multirow[b]{2}{*}{$\begin{array}{l}\text { Kansei } \\
\text { Words }\end{array}$} & \multicolumn{4}{|c|}{ Footer } \\
\hline & & & $\begin{array}{l}5 \\
5 \\
5 \\
0 \\
0 \\
8 \\
80 \\
0\end{array}$ & 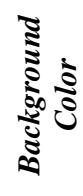 & 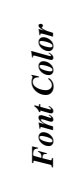 & 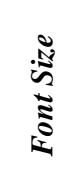 \\
\hline 1 & Cozy & Nyaman & Left & Blue & Green & Fair \\
\hline 2 & Easy & Mudah & $N / S$ & Grey & Green & Fair \\
\hline
\end{tabular}




\begin{tabular}{|c|c|c|c|c|c|c|}
\hline \multirow[b]{2}{*}{ No } & \multirow[b]{2}{*}{$\begin{array}{l}\text { Konsep } \\
\text { Desain }\end{array}$} & \multirow[b]{2}{*}{$\begin{array}{c}\text { Kansei } \\
\text { Words }\end{array}$} & \multicolumn{4}{|c|}{ Footer } \\
\hline & & & 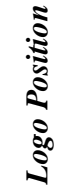 & 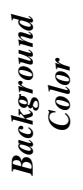 & $\begin{array}{l}\grave{\Xi} \\
\vdots \\
\vdots \\
\vdots \\
0\end{array}$ & $\begin{array}{l}\tilde{N} \\
\tilde{\Xi} \\
\tilde{\Xi}\end{array}$ \\
\hline 3 & Creative & Kreatif & Left & White & Black & $N / S$ \\
\hline
\end{tabular}

Dari salah satu usulan baru perancangan website untuk konsep desain 'Coziness' tersebut dapat menjadi acuan untuk membuat perancangan baru. Sedangkan untuk konsep desain 'Easiness' akan menghasilkan interpretasi sebagai berikut:

a. Untuk kategori body kita dapat mengalokasikan font color berwarna putih dan font size medium dengan background color bebas dan background style bebas karena bernilai 'not significant'.

b. Kemudian untuk kategori top menu kita dapat menempatkan position sebelah kanan halaman website mobile, tanpa background color karena bernilai none dan akan mengikuti body background color atau putih tanpa background jika body background bernilai kosong dengan font color hitam dan font size medium.

c. Sedangkan untuk left menu tidak ada yang perlu disarankan karena seluruh elemen bernilai 'not significant' dan dapat diabaikan.

d. Untuk header dapat mengalokasikan font color berwarna ungu dan font size small.

e. Yang terakhir untuk footer dapat dialokasikan background color abu-abu dan font color berwarna hijau dan font size medium.

Namun interpretasi diatas masih fokus terhadap satu macam kansei words tanpa melakukan asimilasi diantara dua atau lebih kelompok kansei words sehingga menghasilkan interpretasi berbeda dengan hasil analisis awal dari matriks usulan awal.

\subsection{Inovasi menggabungkan hasil analisis faktor multivariat.}

Adakalanya ketika hasil analisis yang telah disusun harus siap dengan beberapa kemungkinan lain, yaitu hasil view sample yang dapat dijadikan acuan bahan perancangan website baru, dengan alasan tersebut penulis mencoba mengkombinasikan konsep analisis multivariat tertinggi yang dihasilkan antara Faktor ke 1 dan Faktor ke 2 dari masing-masing kelompok kansei words. Sehingga menghasilkan konsep desain gabungan seperti terlihat pada Tabel 9.

Tabel 9. Rencana asimilasi kansei words faktor satu dan faktor dua.

\begin{tabular}{|c|l|c|}
\hline No & Responden & $\begin{array}{c}\text { Hasil Analisis Multivariat } \\
\text { Gabungan }\end{array}$ \\
\hline 1 & $\begin{array}{l}\text { Seluruh } \\
\text { Responden }\end{array}$ & Coziness diasimilasi Uniqueness \\
\hline 2 & Pria & Easiness diasimilasi Luxurious \\
\hline 3 & Wanita & Creative diasimilasi Calmness \\
\hline
\end{tabular}

Dengan menggunakan langkah-langkah seperti yang sudah dilakukan dimana data output dari proses PLS diolah dengan tujuan mendapatkan nilai elemen tertinggi yang dapat dijadikan matriks usulan terhadap perancangan website baru, Maka terdapat sedikit perbedaan proses dalam inovasi menggabungkan kansei words menggunakan nasil analisis faktor multivariat untuk mendapatkan view sample baru, dimana dua kansei words dengan nilai faktor tertinggi antara F1 dan F2 dari setiap kelompok responden digabungkan dalam satu alur proses hingga didapatkan matriks usulan yang berbeda jika dibanding dengan hanya menggunakan satu kansei words tertinggi.

Tabel 10. Inovasi matriks usulan tampilan website kategori 'body' untuk responden pria

\begin{tabular}{|c|c|c|c|c|c|c|}
\hline \multirow[b]{2}{*}{ No } & \multirow[b]{2}{*}{$\begin{array}{c}\text { Konsep } \\
\text { Desain }\end{array}$} & \multirow[b]{2}{*}{$\begin{array}{c}\text { Kansei } \\
\text { Words }\end{array}$} & \multicolumn{4}{|c|}{ Body } \\
\hline & & & 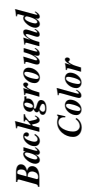 & 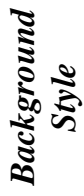 & $\begin{array}{l}\vdots \\
\vdots \\
0 \\
\vdots \\
0\end{array}$ & 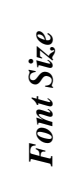 \\
\hline 1 & Easy & Mudah & $N / S$ & $N / S$ & White & Fair \\
\hline 2 & Luxury & Mewah & None & Pict & $N / S$ & $N / S$ \\
\hline
\end{tabular}

Tabel 11. Inovasi matriks usulan tampilan website kategori 'top menu' untuk responden pria

\begin{tabular}{|c|c|c|c|c|c|c|c|}
\hline \multirow[b]{2}{*}{ No } & \multirow[b]{2}{*}{$\begin{array}{c}\text { Konsep } \\
\text { Desain }\end{array}$} & \multirow[b]{2}{*}{$\begin{array}{l}\text { Kansei } \\
\text { Words }\end{array}$} & \multicolumn{5}{|c|}{ Top Menu } \\
\hline & & & ڤั่ & 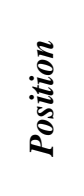 & 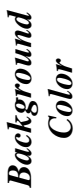 & 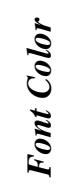 & 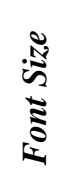 \\
\hline 1 & Easy & Mudah & $N / S$ & Right & None & Black & Fair \\
\hline 2 & Luxury & Mewah & $N / S$ & $N / S$ & None & $N / S$ & Fair \\
\hline
\end{tabular}

Tabel 12. Inovasi matriks usulan tampilan website kategori 'left menu' untuk responden pria

\begin{tabular}{|c|c|c|c|c|c|c|c|}
\hline \multirow[b]{2}{*}{ No } & \multirow[b]{2}{*}{$\begin{array}{c}\text { Konsep } \\
\text { Desain }\end{array}$} & \multirow[b]{2}{*}{$\begin{array}{l}\text { Kansei } \\
\text { Words }\end{array}$} & \multicolumn{5}{|c|}{ Left Menu } \\
\hline & & & हें & 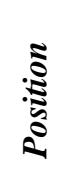 & 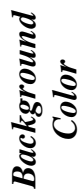 & 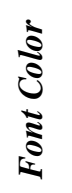 & 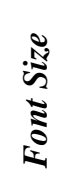 \\
\hline 1 & Easy & Mudah & $N / S$ & $N / S$ & $N / S$ & $N / S$ & $N / S$ \\
\hline 2 & Luxury & Mewah & $N / S$ & $N / S$ & $N / S$ & $N / S$ & $N / S$ \\
\hline
\end{tabular}

Tabel 13 Inovasi matriks usulan tampilan website kategori 'header' untuk responden pria 
Arief Ginanjar ${ }^{1}$ Wahyu Purnama Sari ${ }^{2}$ Herlina ${ }^{3}$, Inovasi Alternatif Perancangan Tampilan Website Berdasarkan Analisis Faktor Multivariat sebagai Bagian dari Implementasi Kansei Engineering

\begin{tabular}{|c|c|c|c|c|c|c|}
\hline \multirow[b]{2}{*}{ No } & \multirow[b]{2}{*}{$\begin{array}{c}\text { Konsep } \\
\text { Desain }\end{array}$} & \multirow[b]{2}{*}{$\begin{array}{c}\text { Kansei } \\
\text { Words }\end{array}$} & \multicolumn{4}{|c|}{ Header } \\
\hline & & & 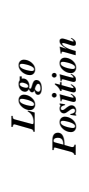 & ن & 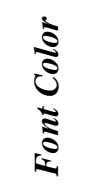 & 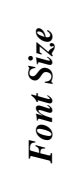 \\
\hline 1 & Easy & Mudah & $N / S$ & Blue & Purple & Small \\
\hline 2 & Luxury & Mewah & Left & None & White & Small \\
\hline
\end{tabular}

Tabel 14 Inovasi matriks usulan tampilan website kategori 'footer' untuk responden pria

\begin{tabular}{|c|c|c|c|c|c|c|}
\hline \multirow[b]{2}{*}{ No } & \multirow[b]{2}{*}{$\begin{array}{c}\text { Konsep } \\
\text { Desain }\end{array}$} & \multirow[b]{2}{*}{$\begin{array}{l}\text { Kansei } \\
\text { Words }\end{array}$} & \multicolumn{4}{|c|}{ Footer } \\
\hline & & & 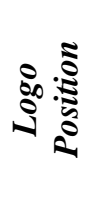 & 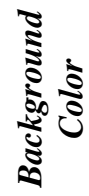 & 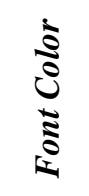 & 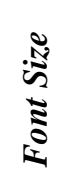 \\
\hline 1 & Easy & Mudah & $N / S$ & Grey & Green & Fair \\
\hline 2 & Luxury & Mewah & $N / S$ & None & White & $N / S$ \\
\hline
\end{tabular}

Dari data matriks yang terdapat dalam Tabel 10 , $11,12,13$ dan 14 kemudian dilakukan interpretasi dengan acuan perancangan berdasar konsep desain 'Easy' yang digabungkan dengan 'Luxury' sehingga akan menghasilkan interpretasi sebagai berikut:

a. Body background disarankan tidak menggunakan warna dengan menggunakan background image namun dengan kondisi header background color menggunakan warna biru maka body background image mayoritas menggunakan warna biru. Kemudian 'body font' disarankan menggunakan warna putih dengan ukuran font medium.

b. Kemudian untuk top menu style karena bernilai 'not significant' berarti tidak perlu didefinisikan secara khusus, dilanjutkan dengan posisi top тепи sebelah kanan halaman website mobile dan tanpa background color atau 'none' dan cenderung mengikuti warna mayoritas body background image, sedangkan untuk font color menggunakan warna hitam dengan ukuran font medium.

c. Sedangkan untuk left mепи tidak perlu didefinisikan karena semua nilai 'not significant'.

d. Kategori header dengan logo position sebelah kiri dan background color berwarna biru, sedangkan font color untuk konsep desain 'easy' berwarna ungu dengan nilai coefficient 0.060 dan konsep desain 'luxury' berwarna putih dengan nilai coefficient 0.024 maka akan dipilih warna ungu dengan pertimbangan nilai coefficient yang tinggi sedangkan untuk font size small.

e. Untuk kategori footer logo position bernilai 'not significant' dan background color berwarna grey dengan font size medium, sedangkan untuk warna font color karena konsep desain 'Easy' dan 'Luxury' menyarankan berbeda warna dimana nilai

background color untuk footer 'Easy' berwarna hijau dengan nilai 0.060 sedangkan untuk 'Luxury' dengan warna putih bernilai 0.025 maka penulis akan menggunakan nilai tertinggi yaitu 0.060 .

Dengan berdasarkan interpretasi yang telah disusun menggunakan penggabungan dua konsep desain 'Easy' dan 'Luxury' maka penulis mencoba menyusun prototype view sample seperti yang terlihat pada gambar 2, 3 serta gambar 4.

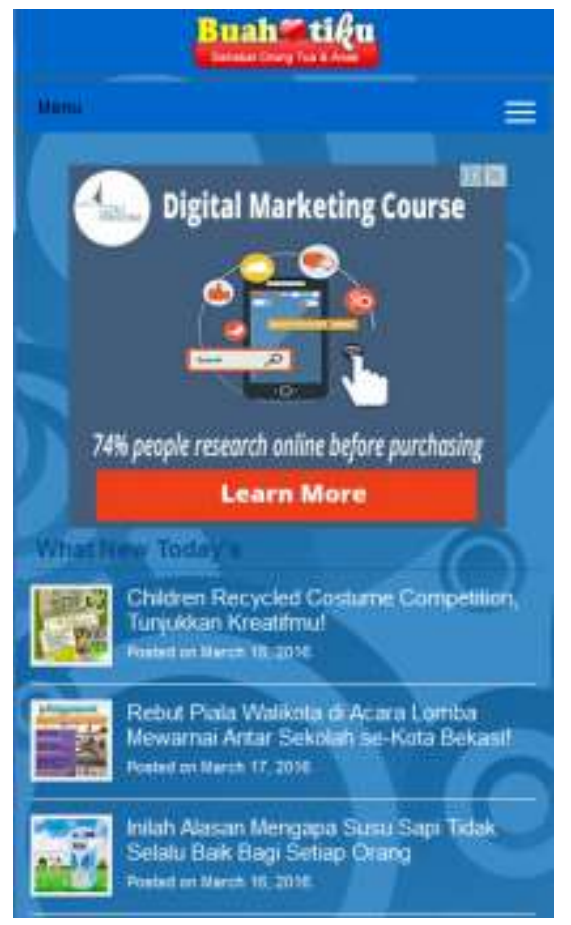

Gambar 2. Tampilan perkiraan bagian atas dari halaman website dilihat melalui mobile browser menggunakan konsep

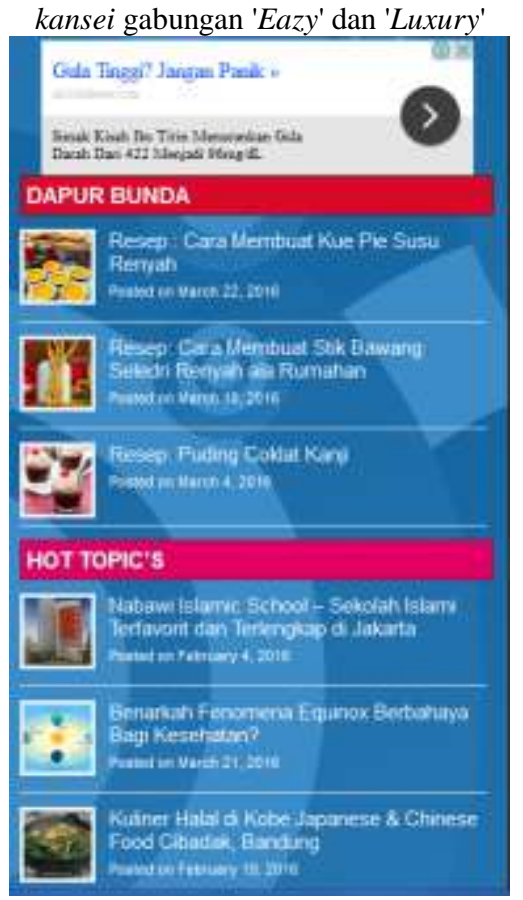

Gambar 3. Tampilan perkiraan bagian tengah dari halaman website dilihat melalui mobile browser menggunakan konsep kansei gabungan 'Eazy' dan 'Luxury' 


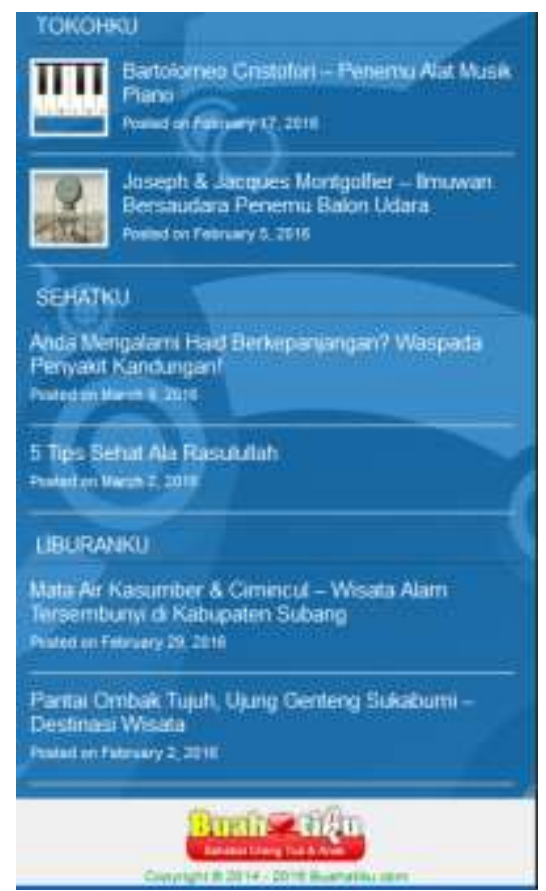

Gambar 4. Tampilan perkiraan bagian bawah dari halaman website dilihat melalui mobile browser menggunakan konsep kansei gabungan 'Eazy' dan 'Luxury'

\section{Kesimpulan}

Perancangan antarmuka website dari sudut pandang mobile browser menggunakan pendekatan analisis faktor multivariat sebagai bagian dari kansei engineering dengan tujuan menghasilkan rekomendasi yang berakar pada faktor psikologis dan selera pengguna.

Terdapat tujuh tahapan yang harus dilakukan untuk menghasilkan perancangan antarmuka yang sesuai dengan psikologis pengguna dan sesuai dengan metodologi [12][13].

Kesimpulan yang berhasil dicapai pada hasil penelitian adalah :

1. Dari tiga kelompok responden yaitu pria, wanita dan seluruh responden telah didapatkan tiga usulan perancangan halaman website dengan menggunakan enam kansei word gabungan yaitu; Cozy, Unique, Easy, Luxury, Creative dan Calm.

2. Matrik nilai elemen website dari sudut pandang website browser merupakan berasal dari kansei word dengan perhitungan analisis faktor multivariat dan digabungkan dengan partial least square dari setiap kelompok responden.

3. Inovasi yang dihasilkan dari enam kansei word seperti yang telah disebutkan dalam nomor kesatu dari kesimpulan ini, kemudian diasimilasikan antara Cozy dan Unique, kemudian antara Easy.dan Luxury serta yang terakhir antara Creative dan Calm.

\section{Daftar pustaka}

[1] Lokman, Anitawati Moch. 2009. Emotional User Experience in Web Design: The Kansei Engineering Approach. Universiti Teknologi Mara (UiTM), Malaysia.

[2] Nagamachi. Mitsuo. et al. 2011. Innovations of Kansei Engineering. CRC Press.

[3] Nagamachi, Mitsuo. 1993. Kansei Engineering on Word Sound. The Acoustical Society of Japan, Japan.

[4] Nagamachi, Mitsuo. 1999. Kansei Engineering: A New Consumer-Oriented Technology for Product Development. The Occupational Ergonomics Handbook, Karwowski, W. and Marras, W. S. (ed.), CRC Press LLC, USA.

[5] Nagamachi, Mitsuo. 2007. Perspectives and new trend of Kansei / Affective Engineering. The 10th International Conference on Quality Management and Operation Development. Linköping University Electronic Press, Sweden.

[6] Lokman, Anitawati Moch., 2010, Design \& Emotion: The Kansei Engineering Methodology. Universiti Teknologi Mara (UiTM), Malaysia.

[7] Smith, Lindsay I., 2002. A tutorial on Principal Components Analysis. University of Otago, New Zealand.

[8] Jolliffe, Ian T., 2002, Principal Component Analysis, Second Edition, Springer-Verlag., New York.

[9] Sharma, S., 1996, Applied Multivariate Techniques. New Jersey: John Wiley \& Sons, Inc.

[10] Johnson, Richard A, and Dean W. Wichern., 2002, Applied Multivariate Statistical Analysis, 5th edition, Prentice Hall Inc., New Jersey.

[11] Mindrajaya, I.G.N., Sumertajaya, I.M. 2008. Pemodelan Persamaan Struktural dengan Partial Least Square. Semnas Matematika dan Pendidikan Matematika. Universitas Negeri Yogyakarta. Yogyakarta.

[12] Ginanjar, A dan Supendi, Y, 2018, Implementasi Kansei Engineering Dalam Perancangan Antarmuka Websiite Mobile Portal Berita Informasi Pendidikan dan Kesehatan Anak., Jurnal TIARSIE, 14(1). Universitas Langlangbuana.

[13] Hadiana, A and Ginanjar, A, 2018, Designing Interface of Mobile Parenting Information System based on User's Perception using Kansei Engineering, Journal of Data Science and Its Applications 1(1), Telkom University. 